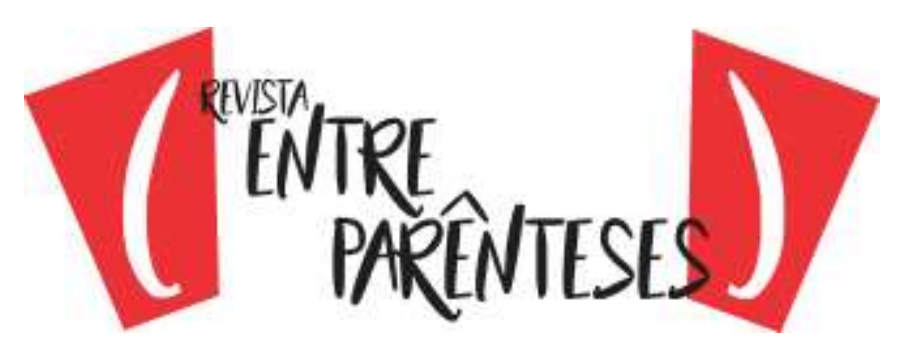

\title{
MÍO CID HISTÓRICO E LITERÁRIO: A CONSTRUÇÃO DO HERÓI CASTELHANO NO ROMANCE XX
}

\author{
https://doi.org/10.32988/rep.v1n9.1131
}

\author{
Gabrielly Araujo ${ }^{1}$ \\ Universidade Federal de Alfenas-MG \\ (gabriellyaj7@gmail.com)
}

\begin{abstract}
RESUMO: Por volta do século XV, aparece na Espanha uma série de poemas épicos conhecidos como romances, que refletiam o contexto histórico e cultural da sociedade da época. No decorrer dos séculos, estes poemas foram reproduzidos e se tornaram parte da identidade castelhana por resguardar traços historiográficos e personagens que foram importantes a este povo. No lugar de protagonistas de alguns destes poemas, surgem heróis históricos e, dentro do gênero, este tipo de personagem adquire grande importância, já que tais textos (re)construíram estas figuras de modo a transformá-las em mitos do período histórico retratado. Assim, este artigo traça uma breve linha do tempo que evidencia algumas das principais manifestações heroicas, no intuito de tentar demonstrar a universalidade desta figura, ao mesmo tempo em que apresenta suas particularidades mais importantes. Além disso, realizou-se uma exposição sobre o protagonista do romance XX, Mío Cid, pelas óticas histórica e literária, a partir das quais se pode perceber diferenças e semelhanças na construção do herói castelhano. Ao final, compreende-se como se dá a representação da figura do herói dentro de tal contexto, e como esta figura mítica pode assumir um papel social e histórico significativo para o imaginário coletivo da época. Palavras-Chave: Romancero Viejo; Herói; Mio Cid; Sociedade Ibérica.
\end{abstract}

\section{HISTORIC AND LITERARY CID MÍO: THE CONSTRUCTION OF THE CASTILE HERO IN ROMANCE XX}

ABSTRACT: Around the 15th century, a series of epic poems known as romances appeared in Spain reflecting the historical and cultural context of the society of the time. Over the centuries, these poems have been reproduced and have become part of the Castilian identity for safeguarding historiographic traits and characters that were important to this people. In the place of protagonists of some of these poems, historical heroes emerge and, within the genre, this type of character acquires great importance, since such texts (re)constructed these figures in order to transform them into myths of the historical period portrayed. Therefore, this article traces a brief timeline that highlights some of the main heroic manifestations, in an attempt to demonstrate the universality of this figure, while presenting its most important particularities. In addition, an exhibition was held on the protagonist of the XX novel, Mío Cid, from the historical and literary perspectives, from which differences and similarities can be seen in the construction of the Castilian hero. In the end, it is understood how the representation of the hero figure takes place in such a context, and how this mythical figure can assume a significant social and historical role for the collective imagination of the period.

Key words: Romancero Viejo; Hero; Mio Cid; Iberian Society.

MíO CID HISTÓRICO y LITERARIO: LA CONSTRUCCIÓN DEL HÉROE CASTELLANO EN EL ROMANCE XX

\footnotetext{
${ }^{1}$ Mestra em História Ibérica e graduada em Letras Espanhol e Português pela Universidade Federal de Alfenas, UNIFAL-MG.
} 


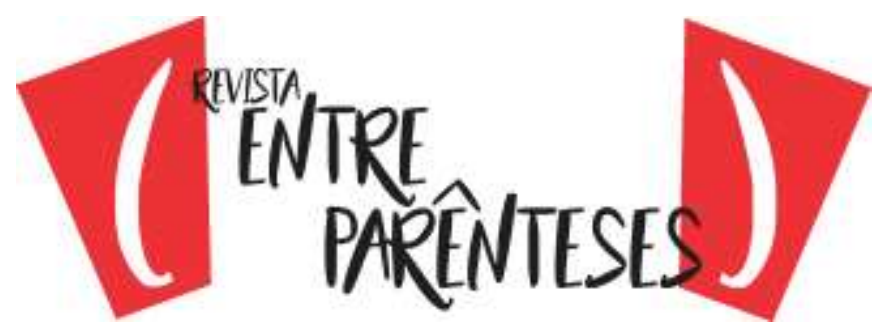

RESUMEN: En el siglo XV surgió en España una serie de poemas épicos conocidos como romances que reflejaban el contexto histórico y cultural de la sociedad de la época. Con los siglos, estos poemas se reprodujeron y se convirtieron en parte de la identidad castellana al salvaguardar rasgos y personajes historiográficos que fueron importantes. En lugar de los protagonistas de algunos de estos poemas, emergen héroes históricos y este tipo de personaje adquiere gran importancia, ya que estos textos (re)construyeron tales figuras para transformarlas en mitos del período histórico señalado. Así, este artículo presenta una breve línea temporal que destaca algunas de las principales manifestaciones heroicas en la intención de demostrar la universalidad de esta figura al mismo tiempo en que apunta sus particularidades. Además, se realizó una exposición sobre el protagonista del romance XX, Mío Cid, por las óticas histórica y literaria, a partir de las cuales se puede percibir diferencias y semejanzas en la construcción del héroe castellano. Al final, se entiende cómo la representación de tal personaje tiene lugar en tal contexto y cómo la figura mítica del héroe puede asumir un papel social e histórico significativo para el imaginario colectivo de la época.

Palabras clave: Romancero Viejo; Héroe; Mio Cid; Sociedad Ibérica.

\section{DESENVOLVIMENTO DO HERÓI}

Desde a madrugada literária de Homero, vê-se o desenvolvimento de um gênero literário que coloca no centro de suas ações o herói. De fato, o termo que dá origem à épica é epos, que se traduz do grego como palavra, fato glorioso ou como narrativa e, hoje, o conceito denomina a literatura versificada e narrada em terceira pessoa, cujo conteúdo aborda a história de um herói ou de uma nação.

Entretanto, muito além de se limitar aos domínios literários, a épica se tornou um gênero cuja influência permeou a realidade de muitas gerações, por ser um dos primeiros recursos criados para contar os grandes feitos históricos das nações e exaltar seus heróis. A primeira epopeia de que se tem conhecimento é a llíada, escrita por volta do século 8 a.C. e de autoria atribuída ao supracitado Homero. Outro texto atribuído ao autor é a Odisseia, que reproduz as aventuras de Odisseu, seu personagem central.

Os personagens das obras mencionadas, apesar de não haver registros que os comprovem também como homens históricos, representam heróis que ilustraram um contexto sociocultural e um imaginário ideológico-religioso. Isso acontece pelo fato de o conceito de herói estar intrinsecamente conectado à concepção de mundo e de homem, sendo, portanto, extremamente dinâmico ao se adequar aos mais diferentes contextos. Desta forma, 


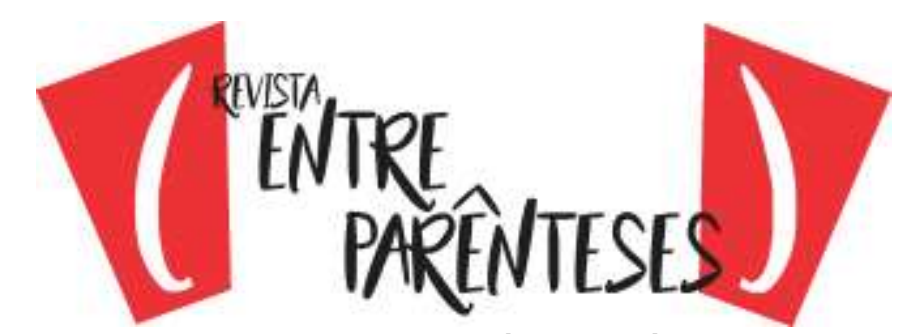

suscribir esta interpretación también conduce a interpretar al héroe en momentos históricos condicionados por el cambio de la concepción del hombre, por cuanto las fuerzas que representan el bien o el mal se metamorfosean, coincidiendo con la visión del mundo (VILLEGAS, 1978, p. 65).

Isto pode ser observado, por exemplo, nas construções heroicas concebidas na Idade Média ou na Idade Moderna após o Renascimento².

Além disso, já nas primeiras obras de Homero percebe-se que os heróis são "hombres de un valor y mérito superiores, favoritos particulares de los dioses" (GARCÍA PEINADO, 1998, p. 72) e essas características se mantêm por muito tempo (até a crise que se instaura no Renascimento). Dessa forma, apesar de serem seres humanos, ou respaldando-se neles, os heróis têm lugar diferente dentro das obras pela sua superioridade e por sua proximidade com o divino, e esse é um dos aspectos mais importantes desse elemento.

Após as configurações iniciadas por Homero, foram desenvolvidos os heróis medievais, cuja compreensão só pode ser completa quando observamos a conjuntura cristã instaurada pelo Império Romano, que alterou as bases divinas que serviam de alicerces para a grandeza do herói homérico.

Os heróis medievais estavam muito mais próximos da realidade de seus conterrâneos (e distantes de Deus), por serem representados por cavaleiros que eram personagens cotidianos daquela sociedade. Talvez por isso tenham exercido mais influência sobre o povo e sobre os séculos subsequentes, já que a maioria dos heróis dessa época foi elaborada a partir de guerreiros históricos pertencentes às mais diversas ordens de cavaleiros.

Então, se em Homero o que tornava os heróis superiores era seu sangue sobrenatural, o que os valorizava na Idade Média tinha um caráter mais "mundano": suas linhagens, posses e seus valores morais. Desse modo, o que thes permitia estar próximos da figura representativa do celestial na terra (o rei), era a posição social, bem como a forma como encarnavam os valores da época.

\footnotetext{
${ }^{2}$ Exemplos disso podem ser vistos no herói épico Cid e no anti-herói Lazarillo de Tormes, que traduzem algumas das problemáticas observadas em seu contexto de produção. 


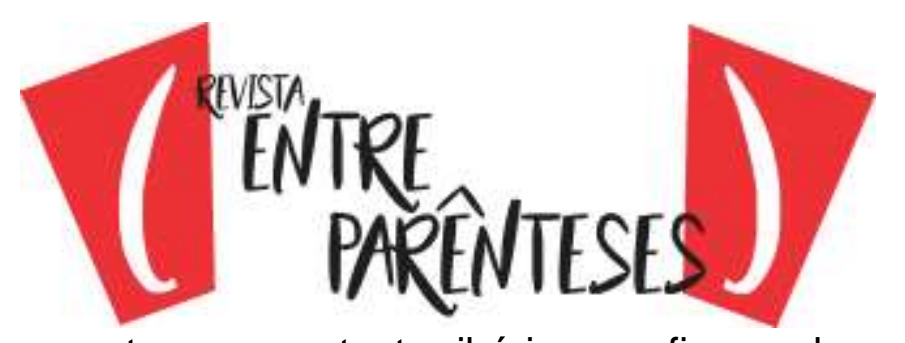

Especificamente em contexto ibérico, a figura do cavaleiro se torna importante por volta do século XII, especialmente por conta do processo conhecido como reconquista, que fundou

uma hierarquização da sociedade em função de critérios militares, a organização de um espaço que não era fechado, e uma visão específica das relações entre o cristão e o seu Criador, que colocava a Igreja numa situação de sujeição ao poder civil (RUCQUOI, 1995, p. 216).

Os cavaleiros ibéricos se agrupavam em diversas organizações. As Ordens de Cavalaria, como ficaram conhecidas as entidades às quais pertenciam os cavaleiros, eram regidas internamente por leis e princípios, dentre os quais são elencados os âmbitos militares e sociais.

Acredita-se que por volta do século XIII a cavalaria já havia se consolidado como um conjunto organizacional bem delimitado no corpo social europeu (DUBY, 1990) e, se inicialmente predominava a heterogeneidade entre os membros da ordem, que provinham das mais distintas posições sociais, aos poucos essa definição se modifica.

Isso ocorre já que, com o passar do tempo, o cavaleiro medieval passa a ser visto como um representante direto dos desígnios divinos, isto é, "o cavaleiro recebera de Deus a missão de combater" (idem, p. 46). Duby (1990, p. 83) estabelece que com as diversas transformações socioculturais ocorridas nesse período - "da noção de "nobreza", sustentada ao mesmo tempo pela imagem de uma antiguidade de raça e pela ideia de autoridade nativa e de poder" -, passa-se "à noção de "cavalaria", estreitamente ligada à noção de serviço militar público" (idem).

Assim, o ideal de cavaleiro almejado por estas Ordens deveria ser, acima de tudo, o de um homem de origem nobre (é ilustrativo o fato de somente os armados cavaleiros montarem a cavalo, mostrando serem superiores ao restante do exército), e leal à Igreja e aos representantes da monarquia. Para completar sua figura, ele deveria, ainda, possuir determinadas qualidades bastante específicas, como a coragem, a generosidade, a sabedoria e a força, entre outras.

A visão heroica medieval só começa a mudar com as transformações provenientes da Renascença, que erigem um personagem que difere dos anteriores 


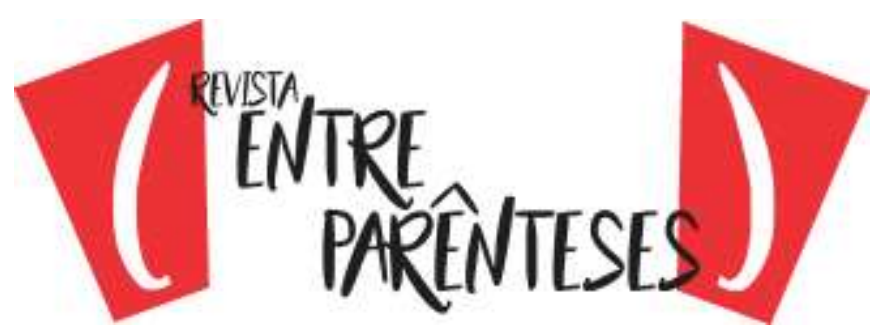

por sua crise com a religião e consigo mesmo. O herói renascentista busca sua identidade, busca conhecer-se e colocar-se diante do mundo, sem desejar outra medida para este. Ainda que o modelo da Renascença tenha recebido uma forte influência clássica, a representação deste herói subverteu os padrões heroicos que haviam sido construídos, firmando uma noção fragmentada e singular de indivíduo que utilizava, sobretudo, as estruturas da realidade como recurso construtivo.

A justificativa para essa fragmentação, segundo Canavaggio (1994), reside no fato de que a literatura do século XVI comportaria as preocupações de um mundo medieval e moderno, simultaneamente. Por isso, se encontrariam três direções distintas nas obras produzidas ou popularizadas nessa época: o caminho que leva de volta à literatura tradicional, o caminho que reflete sobre as civilizações urbanas e o terceiro caminho, que debate os problemas da sociedade e suas conjunturas. Por isso a imagem do herói do século XVI foi sendo reconstruída, uma vez que as bases sociais e culturais também passaram por grande modificação.

Especificamente no contexto da Espanha, esta época foi de profunda crise social, econômica e política: o reinado de Enrique IV de Castela havia terminado, deixando diversos territórios imersos em guerra civil, o povo vivia em condições subhumanas, sem higiene e cuidados, além de que a peste devastava a população.

Dessa forma, a literatura como reflexo pensante da realidade não comportava mais um herói cujos valores se baseassem na grandeza social ou na unidade estrutural e ideológica de um reino conquistador. O contexto sociopolítico castelhano exigia profundidade, crítica e posicionamento, o que não era possível sob o jugo de uma Idade Média predominantemente cristã.

A partir de então, o herói passou a representar e reproduzir as grandes crises modernas: dúvida, amor, morte, solidão e medo, entre tantas outras. Criar uma figura digna de admiração era mais difícil, já que os parâmetros de perfeição foram fracionados. A complexidade desses tempos se reflete em um personagem individualista e bastante trágico, que almeja constelações, mas que tem extrema dificuldade de saber o que sente.

No entanto, além das características específicas dos heróis de diferentes épocas, alguns aspectos são aparentemente imutáveis na figura do herói, e muitos 


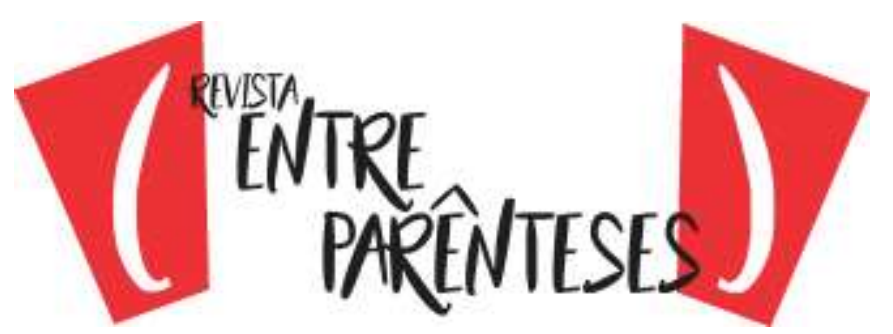

teóricos de Literatura e História, como Villegas (1978) e Fletcher (2002), empreenderam estudos que visassem identificar as razões disso. Além de tudo, por ter sido desenvolvido em quase todas as culturas e contextos históricos, a universalidade do herói sempre foi aspecto de curiosidade e de investigações extensas.

Campbell (1949), por exemplo, em seu livro O herói de mil faces, diz que o herói como o entendemos conseguiu superar as limitações e obstáculos pessoais, históricos e sociais, e alcançou formas humanas elevadas. "As visões, ideias e inspirações dessas pessoas vêm diretamente das fontes primárias da vida e do pensamento humanos" (idem, p. 13) e somente após transcender a esfera humana comum é que os heróis podem falar "com eloquência (...) da fonte inesgotável por intermédio da qual a sociedade renasce" (ibidem).

Então, a Jornada do Herói, tal como é entendida por Campbell, diz respeito a um arquétipo que transcende gerações. Ainda não foi possível dizer o momento exato em que surgiu, o que levou os teóricos a localizarem-na em um tempo primordial (ELIADE, 2016) no qual as coisas estavam em plena formação; mas estudiosos já comprovaram que a Jornada existia no século VIII a. C., como é possível observar com o estudo da llíada.

No entanto, com o passar do tempo, a Jornada do Herói se tornou mítica por recriar e reviver a figura heroica durante as épocas, alterando valores e elementos históricos, sociais e culturais, mas mantendo a grande estrutura arquetípica do homem que se eleva ao se pôr à prova, num grande símbolo de maturação.

É nesse sentido que muitos dos símbolos ou imagens mencionadas na construção heroica constituem rituais primitivos que tentaram auxiliar as civilizações passadas a "cruzarem difíceis limiares de transformação que requerem uma mudança dos padrões, não apenas da vida consciente, como da inconsciente" (CAMPBELL, 1949, p. 9). Isso fez com que passassem a ocupar um lugar de grande relevância em nossa sociedade.

Em resumo, estes rituais compreendem formas de rompimento com uma situação ou mentalidade que devem ficar para trás, de modo que o indivíduo possa progredir em suas relações. Por sua vez, é a partir de tais símbolos e rituais que se 


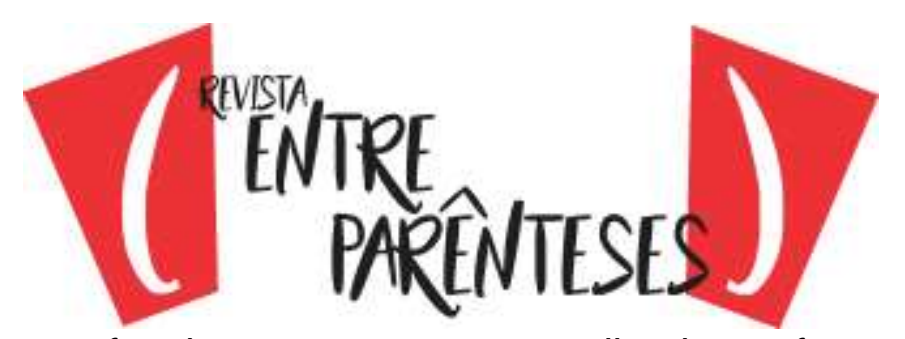

elaboram os mitos, que funcionam como seus catalisadores, fornecendo metáforas e exemplificando as possibilidades de avanço do ser humano. Os símbolos são, deste modo, a linguagem dos mitos, o meio pelo qual se expressam (ELIADE, 2016).

Então, o Mito do Herói tem significado profundo por determinar uma jornada pertencente ao homem, pois apresenta comportamentos e situações como arquetípicas, ou seja, como recorrentes e comuns à maturação do ser humano, e que são realizadas, na grande maioria das vezes, de modo inconsciente.

A Jornada Mítica do Herói se transforma no mais conhecido mito por ter um significado demasiado importante em nossa mente: ela apresenta um material formativo que ensina sobre a origem, sobre o Universo, sobre padrões sociais e morais. As etapas da trajetória do herói refletem precisamente os momentos da vida humana já que a "psique do indivíduo se desenvolve (tal como o mito do herói), a partir de um estágio primitivo infantil" (JUNG, 2016, p. 150).

Desse modo, Campbell (1949) identifica o grande Mito do Herói, em seus termos, como o monomito ao qual todas as sociedades estão sujeitas. Como arquétipo inconsciente e hereditário, o herói é a imagem do homem modelar que venceu seus obstáculos e protegeu e salvou toda sua comunidade. Ele é a força que tenta nos equilibrar e auxiliar em nosso muitas vezes árduo processo de amadurecimento, permitindo que nos localizemos no mundo.

\subsection{CID HISTÓRICO E O CID FICCIONAL}

O personagem Mio Cid é figura importante e relevante na história de Castela, uma vez que permanece sendo uma das grandes representações de heroicidade deste povo. O poema aqui analisado pertence ao conjunto dos romances históricos que tratam de temas nacionais.

A inspiração para a criação literária do personagem parte da existência de um cavaleiro histórico que viveu por volta do século XI. Seu nome era Rodrigo Díaz de Vivar, porém era mais conhecido por Cid campeador, alcunha que vinha do árabe "sidi = senhor e do latim campi doctor = dono do campo de batalha" (GONZÁLEZ, 2010, p. 102). 


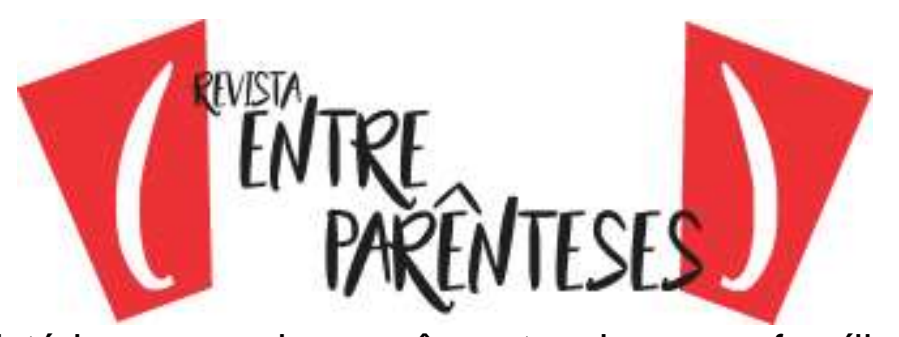

O Cid histórico, segundo se crê, pertencia a uma família da baixa nobreza que vivia ao norte do reino de Castela. Além disso, existem documentos que revelam a presença do avô paterno do herói, Laín Núñez, na corte do rei Fernando I por volta dos anos 1040-1060. Também se constata algo da atuação do pai do Cid, Diego Laínez, em batalhas contra os navarros e em prol da monarquia (SEVILLAQUIÑONES DE LEÓN, 2002, p. 16).

Por outro lado, apesar de que pouco se sabe sobre o lado materno da genealogia de Rodrigo Díaz, "o fato de ter-Ihe sido dado um nome que era comum na família da mãe, e não na do pai, talvez indique que a família materna era bem mais ilustre que a paterna" (FLECTCHER, 2002, p. 150).

Por conta da influência familiar, acredita-se que, desde muito jovem, o Cid já atuasse na corte do rei ao lado de um dos príncipes herdeiros, e aparentemente ele havia sido "colocado na casa do filho mais velho do rei Fernando, Sancho, o herdeiro do trono de Castela. Isso teria ocorrido quando Rodrigo tinha cerca de quatorze anos" (idem p. 151).

Quando, em 1065, o rei Fernando I cai doente após um cerco contra a cidade de Valência e renuncia ao trono, Sancho se torna o rei e com isso o status de Rodrigo deve ter se elevado radicalmente. "O autor da Historia Roderici nos conta que Sancho fez dele comandante de toda a sua milícia, (...) constituindo o núcleo do exército real" (ibidem, p. 157).

Ao lado e em nome de Sancho II, Rodrigo participou de diversas batalhas, inclusive daquela que ficou conhecida como a Guerra dos três Sanchos, de 1067, e foi construindo sua reputação como campi doctor e influente guerreiro. Ao final desse mesmo ano, porém, quando morre Sancha, a viúva de Fernando I, viu-se irromper a guerra civil que se desenrola em decorrência das divisões territoriais estabelecidas pelo rei a seus filhos, que ficaram insatisfeitos com as respectivas posses. Rodrigo luta em favor de Sancho (FERNÁNDEZ DELGADO, 2013, p. 154), porém, após diversas batalhas e tentativas de restaurar a paz, este último é assassinado e seu irmão, Alfonso, apodera-se de seu território.

Assim, da posição de destaque que obtinha sob o poder de Sancho, o cavaleiro passa ao segundo plano sob o domínio do novo monarca. No entanto, em 


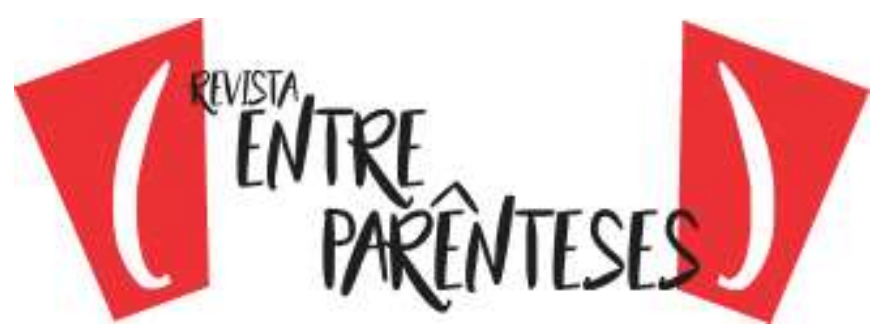

1079, como sinal de reconhecimento, "o rei confiou ao Cid a cobrança dos impostos devidos pelo rei mouro de Sevilha" (GONZÁLEZ, 2010, p. 103).

É nesta ocasião que as hostes de Rodrigo são, como visto em algumas fontes, atacadas pelos mouros, que eram auxiliados pelas tropas de García Ordóñez (conde que posteriormente seria nomeado alférez de Alfonso VI). Porém, estes últimos perdem o embate e deixam Ordóñez sob custódia do Cid por três dias. É esse episódio que dá início às mais diversas especulações sobre a lealdade do herói.

Além disso, diz-se que, em 1081, uma tropa de sarracenos vinda de Toledo invade e toma o castelo de Gormaz, o que parece ter deixado o Cid incomodado a ponto de empreender uma dura retaliação a este reino. No entanto, este ato de justiça decidido por conta própria contrariou diversas pessoas na corte (aparentemente também o rei Alfonso) e deve ter contribuído para que uma atitude mais dura emergisse da parte do rei.

Enfim, por qualquer que tenha sido o motivo, em 1081 Rodrigo é desterrado pela primeira vez. Pela sua popularidade anteriormente conquistada, alguns de seus vassalos decidem segui-lo e o grupo viaja em busca de trabalho, o que, por serem parte da aristocracia, correspondia a encontrar espaço para exercer o ofício de soldado. Assim, em Saragoça, o herói consegue asilo e serve ao rei al-Muqtadir por mais ou menos cinco anos.

Pelo que se sabe, al-Muqtadir tinha problemas de saúde quando empregou o Cid, tendo, por conta disso, dividido os seus territórios entre os dois filhos. Um deles, al-Mu'tamin, deve ter sido mais próximo de Rodrigo, uma vez que a Historia Roderici ${ }^{3}$ nos diz que "este Mu'tamin apreciaba mucho a Rodrigo, y le puso en lugar destacado colocándole al frente de su reino y de todo su territorio, y tomándole en todo de consejero" (FALQUE REY, 1983, p. 346).

Nesse intermeio, acontece uma das batalhas que mais trouxera fama ao Cid. Em Almenar, as tropas do irmão de seu senhor, al-Hayib, se encontraram com as do conde de Barcelona para sitiar o castelo de mesmo nome. O Cid é, então, impelido a lutar contra eles e, por sorte ou sagacidade, sai mais uma vez vitorioso.

\footnotetext{
${ }^{3}$ Historia Roderici é o título da biografia do Cid escrita em latim por autor anônimo por volta dos anos 1180-1190.
} 


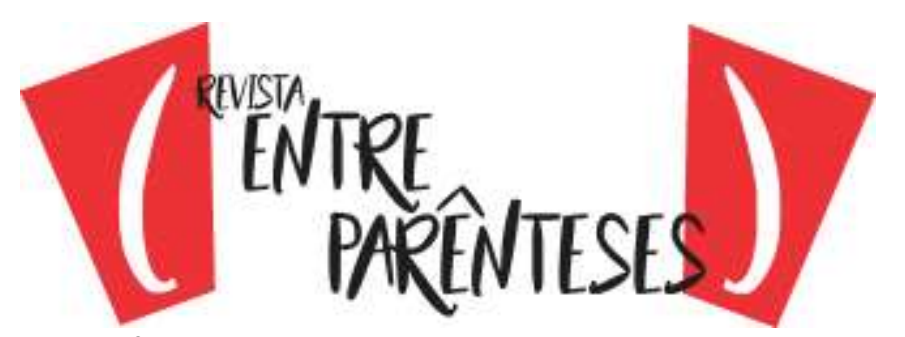

Por sua vez, Alfonso VI, que havia invadido e conquistado Toledo em 1080, começa a empreender sua jornada na obtenção de Saragoça. No entanto, ao saber que um novo e "imenso exército vindo da África do Norte, havia desembarcado no sul da Espanha" (FLETCHER, 2002, p. 192) - o exército dos almorávidas -, o rei reúne suas tropas e parte para enfrentá-los.

Nesse ponto, vê-se que Alfonso resolve perdoar o Cid em função de seu apoio contra a ameaça dos almorávidas. Na Historia Roderici vemos que, além de obter alguns castelos e territórios, Rodrigo ainda conseguiu

el perdón y la concesión escrita en su reino y confirmada con el sello real, estipulando que todas las tierras o castillos que pudiese ganar a los sarracenos, en tierra de éstos, le pertenecerían enteramente y luego a sus hijos, a sus hijas y a toda su descendencia, por derecho hereditario (FALQUE REY, 1983, p. 350).

Assim, sob comando do rei, o Cid parte em 1089 para o sudeste. "Rodrigo encontrou-se com al-Qadir e recebeu o tributo que este devia ao rei Alfonso. Ele permaneceu no principado de al-Qadir para pacificar o território, para isso estabelecese em Requena" (FLETCHER, 2002, p. 207). Nesse ínterim, os muçulmanos voltam à Espanha sob comando de Yusuf, e Alfonso ordena que as tropas de Rodrigo se encontrem com ele para que, juntos, pudessem fazê-los recuar. No entanto, por quaisquer que sejam os motivos, os exércitos não se reuniram e o Cid foi desterrado novamente.

Por conta disso, Rodrigo se dirige para a região do Levante, na qual já havia estado. Por sua proximidade geográfica com o conde de Barcelona, com quem tinha relações difíceis, ele procurou manter-se o mais afastado possível, mas, ao que parece, o próprio conde procurou um embate ao preparar uma armadilha e, no início do ano de 1090, eles se enfrentam. O Cid surpreendentemente sai vitorioso (ele fora cercado de ambos os lados em um terreno bastante irregular), e novamente Berenguer é tomado como prisioneiro.

Após o desenrolar destes eventos, Rodrigo ainda se envolve em outra querela com Alfonso. Percebendo a ameaça que 0 rei castelhano agora the significava, ele passa a procurar aliados e acaba atuando como diplomata entre 


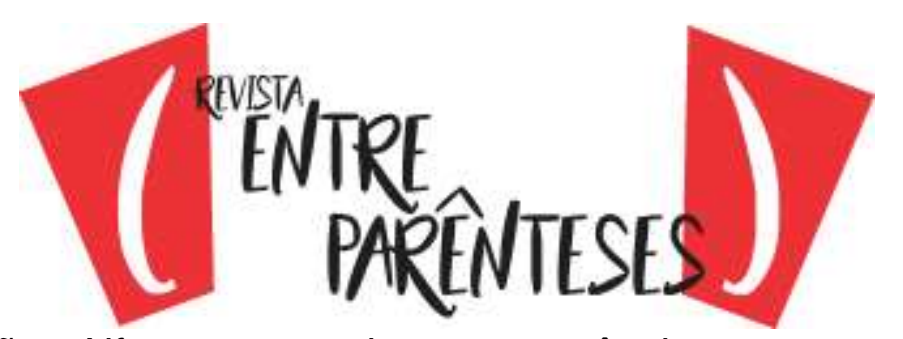

Saragoça e Aragão. Alfonso aproveita sua ausência e empreende um cerco a Valência. Talvez imaginando uma forma de retaliação, Rodrigo invade e devasta a região da Rioja, que pertencia ao território de Castela, e então volta a tomar o poder em Saragoça.

Neste momento, Rodrigo inicia sua campanha em Valência e sitia a cidade a partir da metade de 1093. A cidade se rende em 1094 após um acordo com Ibn Jahhaf, seu governante. O Cid morre em 1099 e Valência só é novamente dominada pelos cristãos em 1236 (GONZÁLEZ, 2010).

De todos esses acontecimentos, pode-se tirar diversas interpretações. Menéndez Pidal (1929), por exemplo, construiu uma grande mitologia ao redor do personagem, elevando-o ao status de herói nacional. Outros, no entanto, acreditam que sua figura deveria ser menos idealizada e mais humanizada, porque, como viuse, muitas de suas ações foram bastante impulsivas e errantes (FUENTES, 2001, p. $61)$.

Como personagem literário, o Cid aparece em bom número de obras. Como se sabe, Rodrigo Díaz de Vivar, em determinado momento, após todos os acontecimentos descritos acima, foi transposto para a obra que primeiro o imortalizou: - Cantar de Mio Cid é um dos textos mais importantes das letras castelhanas e foi responsável por apresentar às próximas gerações um dos heróis mais significativos para o imaginário dessa sociedade. Apresentando uma estrutura incomum para a época (com o desenvolvimento da liberdade formal que é observada nos versos da obra e na construção de "um estilo épico que abre espaço para aspectos dramáticos e até líricos" (GONZÁLEZ, 2010, p. 105), o Cantar tem grande valor literário e utiliza tais elementos para conduzir o leitor à exaltação de seu protagonista (idem).

Alguns dos aspectos que povoam as descrições e ações do herói castelhano são semelhantes aos presentes na construção do personagem literário. De fato, o início da épica se dá com o desterro do cavaleiro pelo rei Alfonso VI, mas acredita-se que algumas folhas no começo do códice se perderam e, com elas, o motivo do desterro do herói literário.

Após o desterro, o Cid se despede de sua mulher Jimena em Burgos e segue viagem para fora de Castela, onde conquista muitas batalhas sobre mouros e 


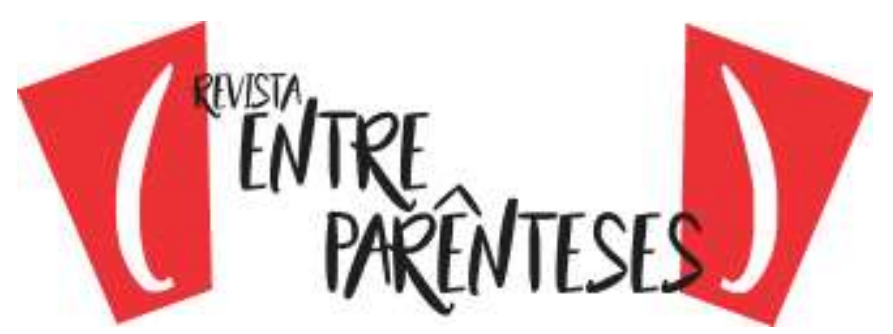

derrota o conde de Barcelona. Diante das pilhagens conseguidas em suas aventuras, Mio Cid sempre selecionou uma parte delas em prol de seu rei, pois pretendia obter o perdão real.

A continuação, o Cid conquista a cidade de Valência, que estava em poder dos mouros. O rei Alfonso, então, liberta sua esposa e suas filhas, que vão de encontro ao herói. "O enriquecimento do Cid leva dois nobres leoneses, os infantes de Carrión, a pedirem ao rei a mão das filhas do Cid. O rei, ao mesmo tempo em que perdoa Rodrigo, transmite o pedido" (GONZÁLEZ, 2010, p. 105).

Depois da celebração do casamento, os infantes permanecem em Valência, onde se conhece sua covardia: "En Valencia estaba Mío Cid con todos sus vasallos // con él sus dos yernos los infantes de Carrión" (ANÓNIMO, 2008, p. 199) e então "se escapó de la jaula y se desató el león" (idem); os irmãos reagem de maneira semelhante e enquanto um deles se enfia debaixo de um banco para esconder-se o outro vai para detrás de uma viga. Eles se sentem ridicularizados por isso e decidem vingar-se em suas esposas. Os infantes partem para Carrión com as filhas do herói, porém, no meio do caminho as machucam e as abandonam. Quando toma conhecimento disso, o Cid exige um julgamento que puna os nobres, o qual acontece em Toledo, onde ambos são despojados de seus bens e riquezas e o Cid recupera sua honra ("Bien honrados se parten los del Campeador, // ganaron este combate igracias a Dios!' (ANÓNIMO, 2008, p. 297).

O personagem Cid foi ainda retomado diversas vezes pelos mais diferentes tipos de textos. Por exemplo, pode-se mencionar os ensaios produzidos por Pedro Salinas, Dámaso Alonso e Gerardo Diego, na Geração de 27; o poema de Rafael Alberti, Entre el clavel y la espada; as biografias de María Teresa León, Rodrigo Díaz de Vivar: El Cid Campeador, de 1954, e Doña Jimena Díaz de Vivar, gran señora de todos los deberes, em 1960, entre tantos outros materiais históricos e literários.

A história cidiana foi resgatada também na Guerra Civil Espanhola por Francisco Franco, que viu nesta figura um exemplo de herói castelhano e por meio da qual se utilizou para legitimar os atos de seu governo. Depois desse episódio, o Cid passa a ser objeto de disputa, já que diferentes linhas ideológicas tentaram tomá-lo como símbolo. 


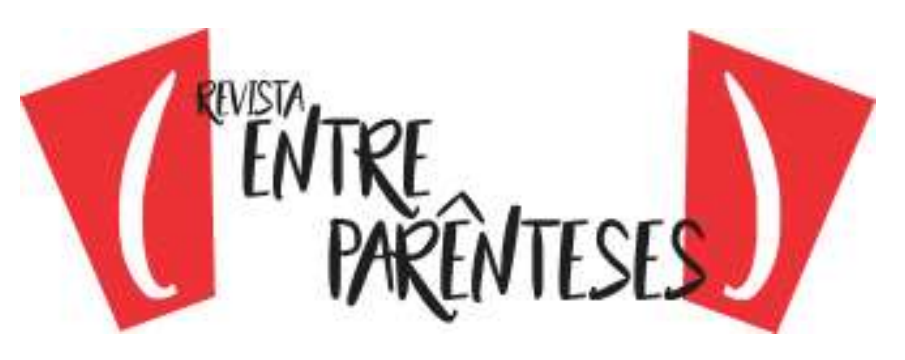

\section{ROMANCE XX}

No poema de número XX, que se inicia com "En Santa Águeda de Burgos, // do juran dos hijosdalgo" (DURÁN, 1945)4, observa-se um contexto que se passa imediatamente após os eventos que retrataram o cerco de Zamora e morte do rei Sancho II.

Sabe-se, já pelos primeiros versos, que a Corte se encontra na igreja de Santa Águeda de Burgos e que os fidalgos estão tomando um juramento do rei Alfonso VI. Aquele que está à frente de todos é o Cid, que tem o crucifixo e as escrituras sagradas na mão. Ele então profere as seguintes palavras:
- Villanos te maten, Alonso, villanos, que no hidalgos, de las Asturias de Oviedo, que no sean Castellanos; mátente con aguijadas, no con lanzas ni con dardos; (...) si no dices la verdad de lo que eres preguntado, sobre si fuiste o no en la muerte de tu hermano.

O desafio feito pelo Cid ao rei é direto e não deixa espaço para dúvidas. Ele exige que Alfonso jure não ter tido nada a ver com a morte do irmão, Sancho, e que o jure sobre as palavras sagradas, ou seja, tendo Deus como testemunha. Ele amaldiçoa ao rei e deseja que tudo o que for mais vil e desonrado possa the acontecer caso minta. O rei, talvez assustado pela força das palavras do Cid, nada responde.

Nisso, um terceiro cavaleiro intercede e pede que Alfonso então jure por ser um bom rei e nada dever. Ele então faz o juramento, porém irado, profere a seguinte resposta:

\section{- ¡Muy mal me conjuras, Cid!}

\footnotetext{
${ }^{4}$ Todos os trechos citados de romances foram retirados da edição de Durán, 1945, disponível em http://www.cervantesvirtual.com/obra-visor/romancero-viejo--0/html/fedb667c-82b1-11df-acc7002185ce6064_51.html.
} 


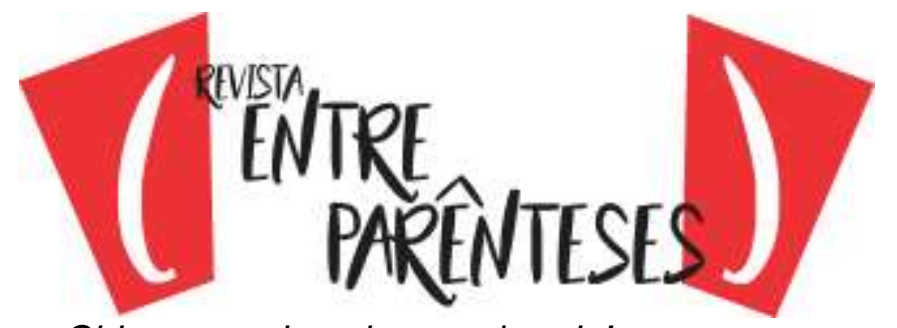

¡Cid, muy mal me has conjurado!

Porque hoy le tomas la jura, a quien has de besar la mano.

Vete de mis tierras, Cid, mal caballero probado, y no vengas más a ellas dende este día en un año.

Alfonso expõe duramente Cid, que agora tem de beijar a sua mão, num indicativo de submissão. Então, ele o desterra por um ano. A resposta dada por Rodrigo, ainda que em posição de vassalo, é igualmente dura: "-Pláceme, dijo el buen Cid, // pláceme, dijo, de grado, // por ser la primera cosa // que mandas en tu reinado. // Por un año me destierras, // yo me destierro por cuatro".

Vê-se que, insatisfeito com a punição já dada por Alfonso, o Cid faz questão de aumentar o tempo do desterro em quatros anos. Ao sair, no entanto, trezentos vassalos o seguem ("Ya se partía el buen Cid, // a su destierro de grado // con trescientos caballeros"), todos jovens e de arma em punho, e, ainda que exilado, não faltou ao herói lugar onde se acomodar.

Dentre os ocorridos no poema, o que se destaca é a questão do desterro do Cid, para o qual há muitas versões. Uma das mais consideradas é a que aparece no Historia Roderici que vai explicar que, após o episódio da cobrança de impostos em Sevilha, no qual Rodrigo interfere em um desentendimento entre dois reis mouros, ele volta para a corte e não é bem recebido pelo rei.

Em outra das versões, logo que Rodrigo retorna a Castela, Alfonso VI parte de lá, pois os sarracenos se haviam rebelado e ele deseja pacificar o reino. Entretanto, assim que o rei deixa o território, estes sarracenos invadem o castelo de Gormaz e pilham-no. O Cid, que não havia ido à primeira perseguição, fica colérico e resolve fazer justiça: assim,

reunido su ejército y bien armados todos sus soldados, saqueando en el reino de Toledo y arrasando la tierra de los sarracenos, hizo prisioneros a siete mil, entre hombres y mujeres, les quitó valerosamente todas sus pertenencias y riquezas, y las llevó a su casa (FALQUE REY, 1983, p. 345). 


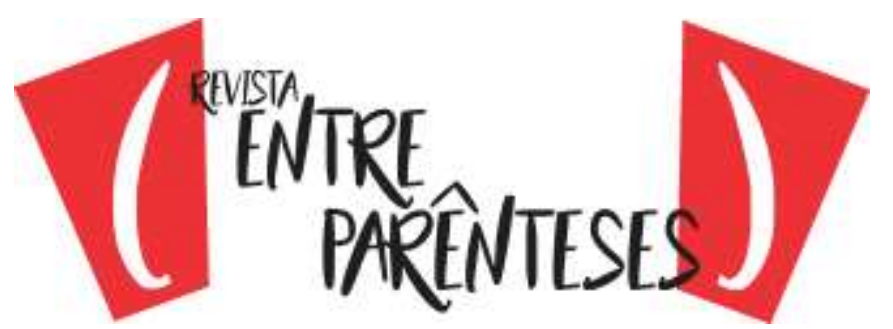

Por conta dessa atitude, segundo a biografia anônima de Rodrigo (idem), toda a corte teria ficado irritada e a inveja fez com que se voltasse a Alfonso pedindo por uma punição. Nesse caso, percebe-se que o exílio do Cid foi causado por sua atuação duvidosa e irresponsável contra a cidade de Toledo. Além disso, muito provavelmente, Alfonso, ao ver a sua autoridade sobrepujada, aproveitou-se a ocasião para enfim puni-lo.

Essa versão também é apresentada por Richard Fletcher (2002) em seu livro Em busca de El Cid. Para o historiador, seu

ato de 'livre-atirador' foi insubordinado e irresponsável. (...) Ameaçava o frágil equilíbrio do protetorado cristão, além de dar um perigoso exemplo a outros turbulentos senhores da fronteira (idem, p. 179).

Alfonso teve, então, de dar provas de suas intenções para com os seus protegidos (como al-Qadir, que havia sido colocado no trono de Toledo por ele) e, por esse motivo, decide banir o Cid.

Além disso, o que conta o romance sobre o desterro de Rodrigo ter sido a primeira ordem dada por Alfonso enquanto rei de fato deve ter se originado da ficção do herói, uma vez que o evento ocorre por volta do ano 1081 (FLETCHER, 2002), período em que Alfonso já estava há cerca de dez anos governando.

Já sobre o tempo do desterro, este romance parece estar mais ou menos próximo ao que se vê no discurso historiográfico. Viu-se que, quando Alfonso o desterra por um ano, o Cid se exila por quatro. Esse período corresponde ao primeiro desterro de Rodrigo, que acontece, como se viu, em 1081. Depois disso, ele demorou cinco anos para retornar a Castela como vassalo do rei. No entanto, pouco tempo depois, em 1088, ele é desterrado novamente.

Por fim, sobre o evento descrito neste romance, o juramento do rei perante sua corte, não há fontes comprobatórias. Inclusive, é dito por Rodríguez e Aja (2007, p. 5) que não houve

juramentos en la iglesia de Santa Gadea; ni enemistad del Rey ni destierro por este motivo. Esas son leyendas elaboradas en épocas más tardías. Al revés, en un principio, el Cid gozó de la amistad y el favor del Rey más que ningún otro noble de la Corte (idem). 


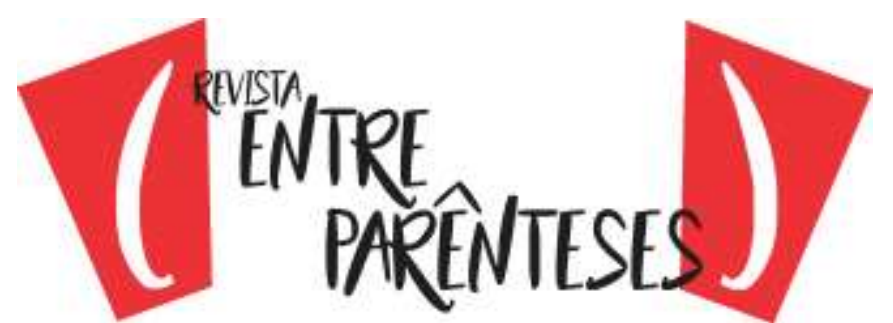

Outra figura que aparece no romance é o rei Alfonso VI. Bastante prolífico na mitologia cidiana, o personagem é conhecido como um dos inimigos mais relevantes do Cid. Filho do rei Fernando I e da rainha Sancha, Alfonso foi um dentre cinco filhos. Alcançando ser rei em 1072, ele unificou sob a sua bandeira os territórios de Leão, Castela e Galícia. Além disso,

[...] os registros públicos colocam Alfonso VI como um dos maiores reis de seu tempo. Monarca coroado por quase 44 anos, por aproximadamente 37 ele governou, com êxito, um reino vasto e em expansão. Ele realizou, com notável brilho, todas as expectativas de um monarca do século XI. (FLETCHER, 2002, p. 163)

As fontes sempre ligam Alfonso à morte de seu irmão, o rei Sancho II. Isso se deve ao fato de que, supostamente, o regicídio foi encomendado pela irmã de ambos, Urraca, a qual apoiava a aspiração do primeiro ao trono. Nada disso pode ser comprovado, mas o fato é que Alfonso e Sancho lutaram por diversos anos.

Ao que tudo indica, Alfonso não teve filhos homens que herdassem sua coroa, pelo que foi precedido por sua filha Urraca I. Sua imagem se ligou à reconquista desde então, mas também ao personagem Cid, já que diversas lendas foram criadas a partir dessa relação.

Muitas fontes afirmam que o relacionamento entre Alfonso e Rodrigo era tênue, baseado majoritariamente na política. Isto seria fundamentado mediante a intimidade que existira entre o irmão do rei e Rodrigo, que já foi mencionada anteriormente, e por conta da qual o Cid teria apoiado Sancho em sua empreitada. Essa perspectiva também pode ir de encontro às controvérsias ocasionadas pelo desterro do herói, apresentadas no Cantar.

Por outro lado, outros registros sugerem que o Cid pode ter sido acolhido com privilégios na corte de Alfonso, que "le recibió como vasallo con honores y le tuvo en la corte en gran estima y consideración" (FALQUE REY, 1983, p. p. 344), fator pelo qual não se pode comprovar a querela.

A imagem heroica que se tem neste poema, que alude ao homem guerreiro, impetuoso e viril, que se arrisca publicamente e que se expõe, se repete na maioria dos romances do ciclo do Cid, sendo um dos elementos que contribui para a 


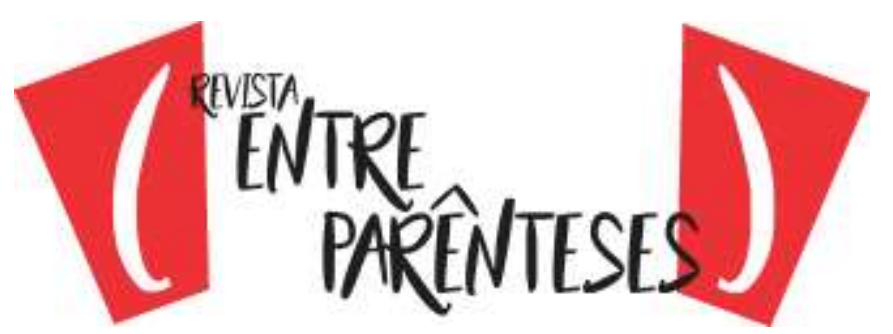

construção da imagem mitológica do herói, pois, nas situações descritas, ele aparece como soldado implacável e austero para as hostes reais: "ese buen Cid castellano" e "Ya se partía el buen Cid, // a su destierro de grado // con trescientos caballeros, // todos eran hijosdalgo", por exemplo. Estes trechos ainda permitem ver características como a impetuosidade e coragem que o transformam em o "maior e o melhor na batalha" (CINTRA, 1951-1961, v. III, 434 apud INFANTE, 2014, p. 216).

É notável que as relações apresentadas neste romance irão salientar a bravura e a impetuosidade do herói diante de outros personagens, inclusive o rei (por exemplo, em “-Villanos te maten, Alfonso, // villanos, que no hidalgos,"). Como se vê, o Cid é altivo, demonstra orgulho de suas riquezas e é, em suma, um homem vitorioso. Percebe-se, no entanto, que a justiça do herói é o aspecto que permeia todo o poema, sendo seu elemento mais proeminente. Isso fica evidente no esforço que o Cid faz para conseguir que Alfonso jure não ser culpado da morte do irmão, outrora o suserano do herói.

Além disso, outra importante faceta do cavaleiro é seu valor, característica que é sempre bastante pontuada nos romances e que colabora para a leitura heroica feita dele. Nos dois últimos versos do poema isto fica em evidência: "Mas no le faltó al buen Cid // adonde asentar su campo". Isso indica que Rodrigo era um homem benquisto na corte, já que comprova o fato de que, ainda que exilado, ele era bem recebido em outros lugares, mesmo que isso significasse que quem o recebia poderia ser alvo da vingança real.

A fama e o reconhecimento do Cid também são características bastante destacadas, visto que exemplificam o ideal de cavalaria no qual o herói deve ser um modelo para os outros membros da sociedade. O herói é tido como um modelo a ser seguido e admirado, o que colabora para a leitura do personagem como cavaleiro ideal, e um homem de valor e mérito superiores (GARCÍA PEINADO, 1998, p. 72), ilustrando que a universalidade de determinados elementos na jornada heroica serve para exemplificar "o fato de que o herói substitui o ser humano exemplar" (MULLER, 2017, p. 18).

Assim, o herói deste poema é imponente e poderoso, uma vez que suas ordens têm o mesmo peso das do rei diante das hostes. Novamente tem-se um Cid 


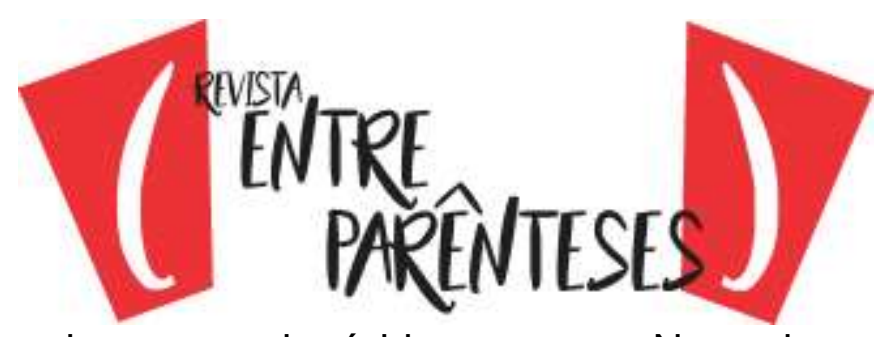

ousado, bravo e um homem mais rígido e severo. Na maior parte do tempo, ele interage com Alfonso como seu igual, mas, ao final, beira a superioridade. Além disso, geralmente o Cid destes romances frequentemente mostra "virtudes e valores humanos mais maduros, como por exemplo, a coragem civil e o desinteressado engajamento social” (MULLER, 2017, p. 9), que fazem dele um herói idealizado e exemplar.

Como se pode perceber, a representação heroica vista na análise mescla elementos clássicos e medievais, o que sugere que a construção do Cid neste romance ilustra a transformação de valores que a sociedade castelhana presenciara entre os anos finais da Idade Média e o começo do Renascimento, período de transição em que os poemas foram transcritos (atente-se para o fato de que temas religiosos quase não aparecem nos romances, sendo essa uma das mudanças que mais facilmente pode ser observada).

Lembrando que algumas das características principais do herói medieval estão relacionadas com nobreza, valentia, ardor guerreiro, generosidade e lealdade (ARIAS FREIXEDO apud MONGELLI, 2012, p. 511), e as do herói clássico remetem à coragem, astúcia e superioridade, compreende-se que as características do Cid vistas nos poemas se integram em um quadro que constrói um personagem heroico arquetípico e universal por "su capacidade evocativa o provocadora, en lo individual y cultural' (VILLEGAS, 1973, p. 45).

Subentende-se, ainda, que os elementos que mais se repetem são os mais proeminentes na construção do mito, pois remetem a uma figura idealizada e glorificada que pode ser admirada mesmo com o passar das gerações (conforme visto na Jornada Mítica do Herói, proposta por Campbell).

O Cid, como herói ideal, diversas vezes vai ser representado seguindo tais princípios, o que exige certos tratamentos atemporais, e os aspectos mais evidenciados nos romances parecem ser inteligíveis desde a Antiguidade por representarem elementos da natureza humana que evidenciam a autorrealização do homem (MULLER, 2017, p. 11). Nesse sentido, é possível encontrar a jornada de um herói que, conforme o tempo passa, vai adquirindo "novos conhecimentos e 


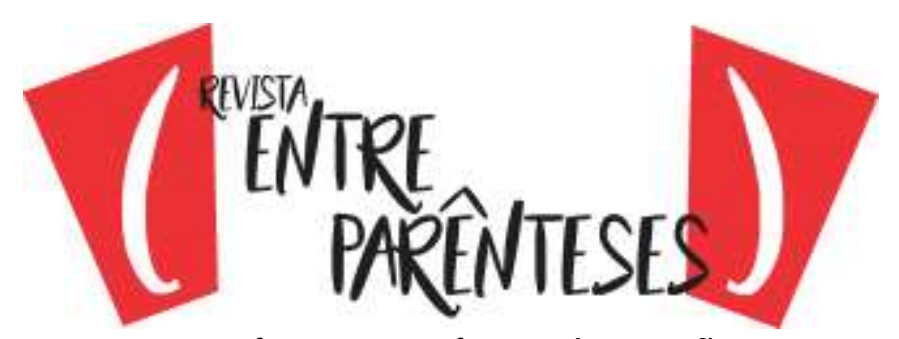

realizações que possuem uma força transformadora, não apenas em relação a ele, mas também à sociedade" (idem).

Por fim, reconhece-se que a integração de elementos históricos permite que o personagem Cid se firme no imaginário castelhano, de modo a representar características fundamentais das quais se necessita "para o domínio da vida e o embate criativo da (nossa) existência" (ibidem).

Isso acontece por conta da transformação do personagem histórico em ficcional, o que anula as características negativas que esta figura poderia ter e dota o herói com um aspecto modelar. Ou seja, quando se tem a transposição da história para a ficção, se estabelece um discurso "melhorado" sobre o passado e sobre a identidade castelhana, o que reforça sua natureza guerreira e conquistadora. É importante lembrar que esta transposição está amparada nos acontecimentos históricos, o que possibilita uma leitura realista e mais verossímil dos discursos produzidos como arte.

Desse modo, por se tornar parte de uma memória coletiva compartilhada pela sociedade castelhana, o Cid se fixa como personagem mítico que reverbera pelos séculos e que institui um modelo heroico.

\section{Referências}

ANÓNIMO. El Cantar de Mío Cid. Madrid: Edimat Libros, 2008.

ARIAS FREIXEDO. Espelho (deformante) da cavalaria: personagens e comportamentos anticorteses nas cantigas de escárnio e maldizer In: MONGELLI, Lênia Márcia. E fizerom taes maravilhas... Histórias de cavaleiros e cavalarias. São Paulo: Ateliê, 2012.

CAMPBELL, Joseph. O herói de mil faces. Trad. Adail Ubirajara Sobral. São Paulo: Editora Cultrix, 1949.

CANAVAGGIO, Jean. Historia de la Literatura Española: La Edad Media. Barcelona:

Editorial Ariel, 1994a.

DUBY, Georges. A sociedade cavaleiresca. Trad. Antônio de Padua Danesi. São Paulo: Livraria Martins Fontes, 1990. 


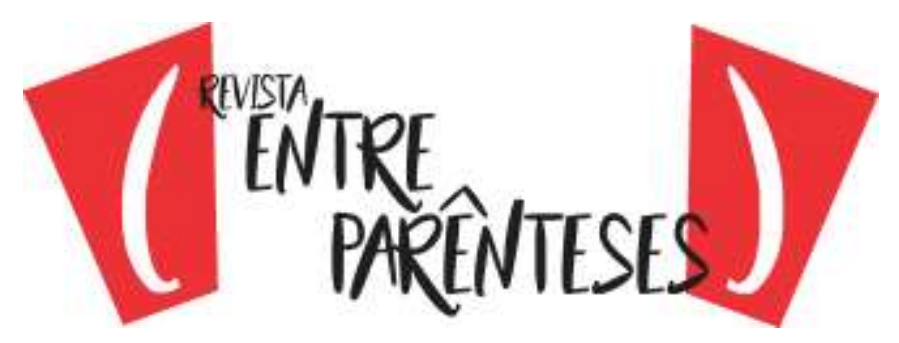

DUBY, Georges; PERROT, Michelle (org.). Historia de las mujeres: La edad media. Espanha: Taurus, 2018.

DURÁN, Agustín (Org.). Romance del Cid y del juramento que tomó al rey don Alonso. In: Romancero general, o, Colección de romances castellanos anteriores al siglo XVIII. [S. I.], 1945. Disponível em: <http://www.cervantesvirtual.com/obravisor/romancero-viejo--0/html/fedb667c-82b1-11df-acc7-002185ce6064 51.html>.

Acesso em: 24 jul. 2020.

ELIADE, Mircea. Mito e realidade. Trad. Pola Civelli. São Paulo: Perspectiva, 2016.

FALQUE REY, Emma. Traducción de la «Historia Roderici». Madrid: Universidade de Sevilha, 1983. Disponível em <https://idus.us.es/xmlui/handle/11441/38410>. Acesso em 30 jun. 2018.

FERNÁNDEZ DELGADO, Juan José. El Cid histórico y literario de Toledo. Espanha: Real Academia de Belas Artes e Ciências de Toledo, 2013. Disponível em $<$ https://realacademiatoledo.es/el-cid-historico-y-literario-de-toledo-por-juan-josefernandez-delgado/>. Acesso em 18 jun. 2018.

FLETCHER, Richard. Em busca de El Cid. São Paulo: Editora UNESP, 2002.

FUENTES, Carlos. O Espelho enterrado. Rio de Janeiro: Rocco, 2001.

GARCÍA PEINADO, Manuel A. Hacia una teoría general de la novela. Arcos Libros: Madrid, 1998.

GONZÁLEZ, Mário M. Leituras de Literatura Espanhola (da idade média ao século XVII). São Paulo: Letraviva: FAPESP, 2010.

INFANTE, Joice; ESTEVES, Antonio R.; NASCIMENTO, Magnólia Brasil Barbosa do (org.). A construção do herói na literatura espanhola. In: Hispanismo à brasileira: Homenagem a Mario Miguel González. São Paulo: ABH, 2014. p. 215-232.

JUNG, Carl Gustav et al. O homem e seus símbolos. Trad. Maria Lúcia Pinho. Rio de Janeiro: Harper Collins, 2016.

MENÉNDEZ PIDAL, Ramón. La epopeya castellana a través de la literatura española. Madrid: 1929.

MULLER, Lutz. O Herói: A verdadeira jornada do herói e o caminho da individuação. São Paulo: Editora Cultrix, 2017. 


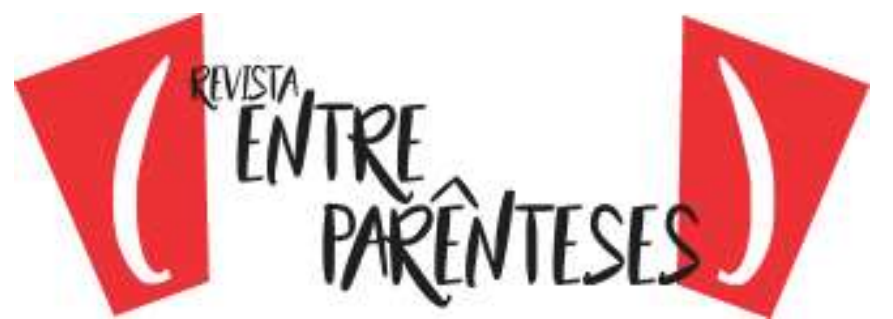

RODRÍGUEZ, Timoteo Riaño; AJA, María Carmen Gutiérrez. El cantar de Mío Cid III: Texto modernizado. Alicante: Biblioteca Virtual Miguel de Cervantes, 2007. Disponível em: <http://www.cervantesvirtual.com/obra/cantar-de-mo-cid-3--textomodernizado-0/ >. Acesso em mar. 2019.

RUCQUOI, Adeline. História medieval da Pensínsula Ibérica. Editorial Estampa: Lisboa, 1995.

SEVILLA-QUIÑONES DE LEÓN, Margarita C. Torre. El linaje del Cid. In: ANALES DE LA UNIVERSIDAD DE ALICANTE HISTORIA MEDIEVAL, 13, 2002, Alicante. p. 6 - $49 . \quad$ Disponível em $<$ https://rua.ua.es/dspace/bitstream/10045/6786/1/HM 13 11.pdf> Acesso em 18 abr. 2019.

VILLEGAS, Juan. La estructura mítica del héroe en la novela del siglo XX. Barcelona: Editorial Planeta, 1978. 